\title{
Numerical Study on the Effect of Structural Parameters on the Behavior of BRBF-E
}

\author{
Bernardo A. Lejano ${ }^{1 *}$, Michael Jayson S. Mas² \\ Associate Professor, De La Salle University, Manila, Philippines, email:bernardo.lejano@dlsu.edu.ph ${ }^{l}$ \\ MSCE Graduate, De La Salle University, Manila, Philippines ${ }^{2}$ \\ *Corresponding author: bernardo.lejano@dlsu.edu.ph
}

\begin{abstract}
Ductile braced frames are often used to resist lateral earthquake loads in steel buildings. However, the presence of the brace element can interfere with architectural features. Buckling-restrained braced frame in eccentric configuration (BRBF-E) is believed to have combined good performance in resisting earthquake loads and great flexibility for architectural design. Eccentrically braced frames can accommodate architectural openings for doors, windows and hallways. However, every configuration of buckling-restrained braced frame in eccentric configuration has a different seismic response in earthquake loadings. The effect of different parameters to the structural response of BRBF-E was studied such as eccentricity-to-length of bay ratio, cross sectional area of BRB, length of the bay, and location of the braces. Design parameters were investigated to determine its effects to the structural response of different eccentric configurations of BRBF-E with building height of 3, 6 and 9 stories. These parameters of BRBF-Es under seismic loading were analyzed using pushover analysis. The analysis of data was composed of comparison of inter-story drift and percentage failure of members. Comparing the different BRBF-E configurations, the single[1] brace configuration provides the most reduction in inter-story drift and percentage of failure of members. From the numerical experiment results, a design guide for BRBF-E was proposed.
\end{abstract}

Keywords-Buckling-Restrained Bracing, Eccentric configuration, pushover analysis, braced steel frame

\section{INTRODUCTION}

$\mathrm{S}_{\mathrm{t}}$ tructural demands of high rise buildings in earthquake-prone countries such as the Philippines require the use of strong lateral framing systems. Structures must have sufficient strength and stiffness to resist seismic forces and assure the safety and stability of the structure during seismic excitation by sustaining large inelastic cyclic deformations. One of the systems used that provides energy dissipation is the BucklingRestrained Braces (BRBs). This is due to its effective response in dissipating energy and inelastic performance under severe earthquakes [1]. Buckling-restrained braces incorporate energy dissipation and provide higher ductility. This in turn reduces inelastic energy dissipation demand on the framing system which can cause structural and non-structural damages. Moreover, buckling-restrained braces are known to be economical dampers for reducing base shear and controlling deformation [2]. The performance of buckling-restrained braced frame generally offers more advantages than other braced frame for buildings three stories and higher [3].

The most common configuration of buckling-restrained braced frame is concentric. Concentric means that the ends of the brace are connected to the node or joint of the frame. Concentric bracings can increase the stiffness of the structure and reduce lateral drift (Tafheem and Khusru 2013). On the other hand, an increase in the stiffness may attract larger inertia force due to earthquake. Furthermore, concentric bracings decrease the bending moments and shear forces in columns, but it increases the axial compression in the columns to which the bracings are connected. Also, concentric configuration can interfere with architectural features [4]. In contrast to this, eccentric bracings reduce the lateral stiffness and improve the energy dissipation capacity of the system [5]. Eccentric means that the ends of the brace are connected at a certain distance from the node of the frame. Due to the eccentric connection of the braces to the beams, the lateral stiffness of the system depends on the flexural stiffness of the beams. Eccentricities in Eccentric Braced Frames (EBF) are introduced at the joints to provide a short portion of beams called "links". Eccentrically braced frames accommodate architectural openings for doors, windows, and hallways. Buckling-restrained braced frames in eccentric configurations (BRBF-E) have combined architectural and performance benefits [4].

This study includes pushover analysis of BRBF-E with configurations such as single diagonal, Chevron $\mathrm{V}$ and Chevron inverted $\mathrm{V}$ using ETABS. The effect of different parameters to the behavior of different BRBF-E was determined to develop a design aid for BRBF-E. The paper explores the behavior of BRBF-E in terms of interstory drift. The paper begins with a discussion of BRBFE parameters. Then, results from pushover analysis of BRBF-E for every parameter are presented and discussed. The established design guide based on the 
The Third International Conference on Civil Engineering Research (ICCER)

August $1^{\text {st }}-2^{\text {nd }} 2017$, Surabaya - Indonesia

results of the numerical experiments for BRBF-E is also explored.

\section{PARAMETERS FOR BRBF-E}

The parameters that which are believed to have effects on the behavior of the BRBF-E [6]. The same parameters were considered in the study. However, this report focuses on the following two parameters 1) eccentricity ratio, and 2) cross sectional area of BRB. Investigation revealed that these two parameters showed most significant effect on the behaviour of BRBF-E. The eccentricity ratio was studied in terms of the eccentricity - length of bay ratio as defined in the work of Prinz (2010). To determine the effects of the eccentricity ratio, the initial model of BRBF-E was modified with a varying eccentricity- length of bay ratio. The eccentricity ratio varies from 0.1 to 0.9 and an interval of 0.05 was used. For the second parameter, an increase in area from the initial cross-sectional area of BRB was made to determine its effect on the performance of the BRBF-E system. An interval percentage change of $10 \%$ up to $100 \%$ was made. But for the purpose of the design guide, the available area of BRB was used.

\section{MODEL FOR FRAMES}

Steel frame structures consisting of three building heights (three, six and nine stories) with three bays were modelled. Bare frames were hypothetically modeled as 3-dimensional systems in which they are symmetrical in both directions. The building height per story was $3.2 \mathrm{~m}$ which can be measured
$6 \mathrm{~m}$. The foundation of the building is assumed to be adequate and will not fail. The model consisted of steel beams, steel column and concrete slab. The dimension of the structure is shown in Figure 1.

The bases of the columns at the ground floor were considered fixed. Both beams and columns are made of steel wide flange, having a yield strength of $345 \mathrm{MPa} \quad(\mathrm{Fy}=345 \mathrm{MPa})$. The floors were assumed to be rigid diaphragm made of normal weight concrete. The floor mass was lumped into the column nodes at each story.

The design of the bare frame (without braces) was done using the equivalent lateral force procedure in ETABS. After the bare frame was designed, the BRBF-E parameters and the BRB were incorporated in the frame structure. Figure 2 shows the configuration used in this study where (a) single configuration (b) Chevron $\mathrm{V}$ at the inner bay (c) Chevron Inverted- $\mathrm{V}$ at the inner bay.

Plastic hinge model was applied to beams and columns to simulate the yielding of these elements. For beam elements, the hinge type used was the Moment M3 (Deformation Controlled) and has an isotropic hysteresis, while for column elements, the interacting P-M2-M3 (deformation controlled) was used as a hinge type and has also an isotropic hysteresis. For the buckling-restrained braces in the BRBF-E, Star Seismic buckling-restrained braces were used in which axial forces and deformations

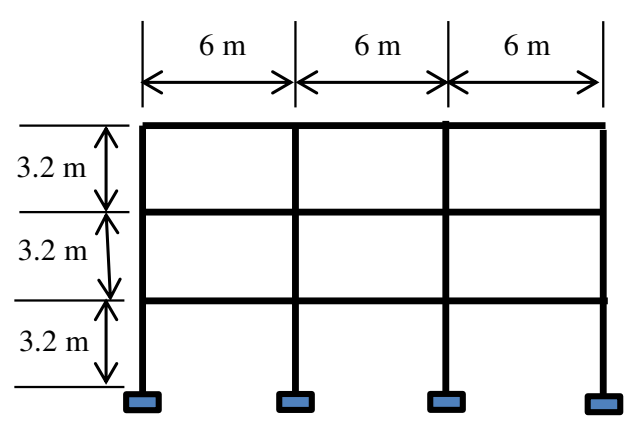

Elevation plan of 3-story steel building

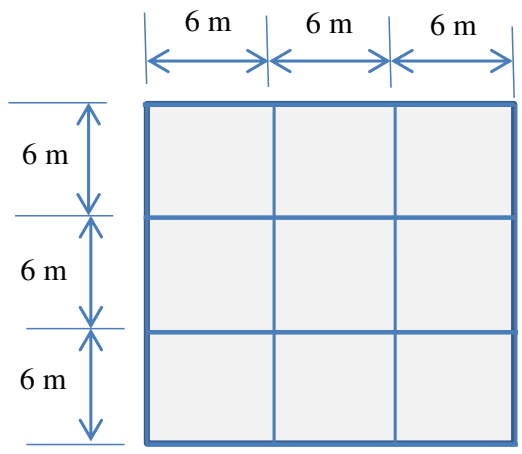

Typical floor plan

Figure 1. Framing details of the hypothetical steel building used in the study.
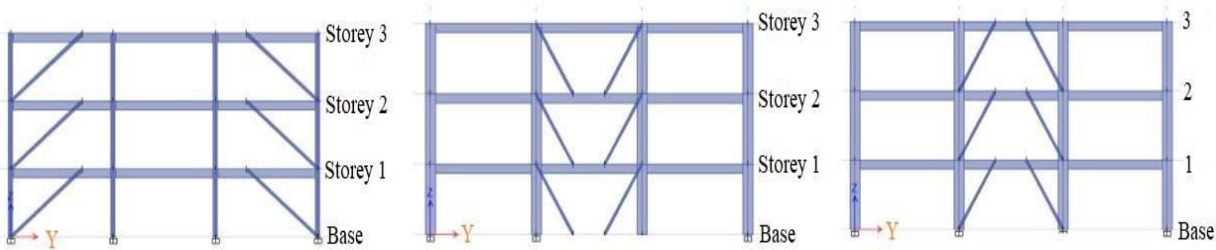

Figure 2. Configuration of BRBF-E.

from center-to-center. The length of the bay was 
The Third International Conference on Civil Engineering Research (ICCER)

August $1^{\text {st }}-2^{\text {nd }} 2017$, Surabaya - Indonesia

were resisted. An axial nonlinear hinge was applied to $\mathrm{BRB}$. The braces have pinned connection.

\section{PUSHOVER ANALYSIS}

In order to carry out the analysis of the building, pushover analysis was used to determine the structural response of the BRBF-E for each parameter. The pushover was done by applying small increment of force until the seismic load was reached. To have different level of seismic load, the seismic load that was calculated for the bare frame was increased by multipliers of 1,2 and 3 .

The pushover curves of each BRBF-E were compared to the bare frame for different number of stories as shown in Figure 3. Each BRBF-E analysed has a constant eccentricity ratio of 0.1 and cross section area of BRB of $6.5 \mathrm{~cm}^{2}$. The pushover curve shows the plot of applied base shear against the monitored displacement at the top story. Three pushover curves are shown corresponding to the three multipliers $(1,2$, and 3$)$ and are indicated as $\mathrm{x} 1, \mathrm{x} 2$ and $\mathrm{x} 3$. As shown in the Figure 3, the increase in the displacement of the structure at the top story as the base shear increases was decreased with the introduction of BRB in certain configuration. The initial slopes of the pushover curves for all configurations were marginally the same. But as it reaches the maximum base shear applied, it was observed that the single diagonal brace configuration has largest decreased in displacement. This is followed by Chevron Inverted-V and, lastly, Chevron V configuration which has the least reduced displacement for all number of stories considered.

This inter-story drift was also investigated. Figure 4 shows the effect of the varying structural parameters on the performance of BRBF-E in terms of inter-story drift. The allowable drift was used as a limit for the analysis. The allowable drift or drift limit has the equation of: $\Delta$ limit $=0.01 \mathrm{~h}$, which is based on the code (ASCE 7-10). The inter-story drift of the bare frame was used as comparison and the drift limit was used in setting the threshold.

\section{A. Effect of eccentricity ratio}

The summary of the inter-story drift of BRBF-E for different eccentricity ratio under different seismic load multiplier is shown in Fig. 4. These figures only show the lowest and highest inter-story drift to determine the

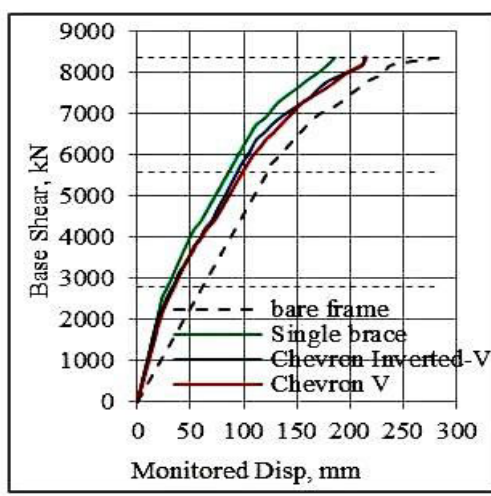

(a)

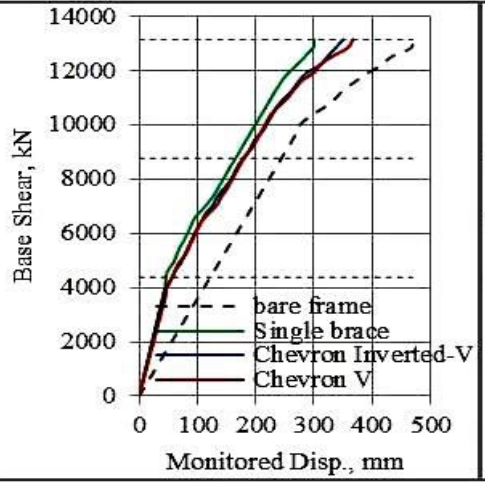

(b)

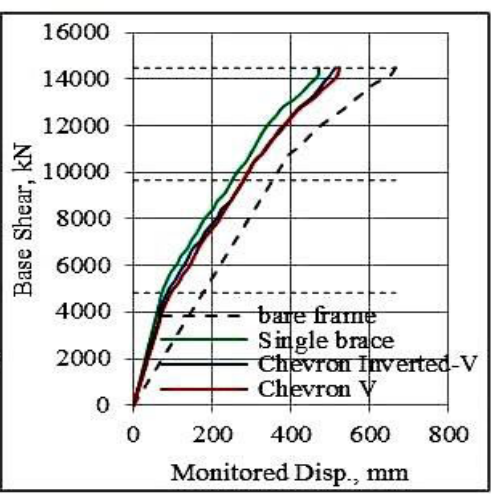

(c)

Figure 3. Pushover Curves (a) 3 Story building; (b) 6 Story building; and (c) 9 Story building.

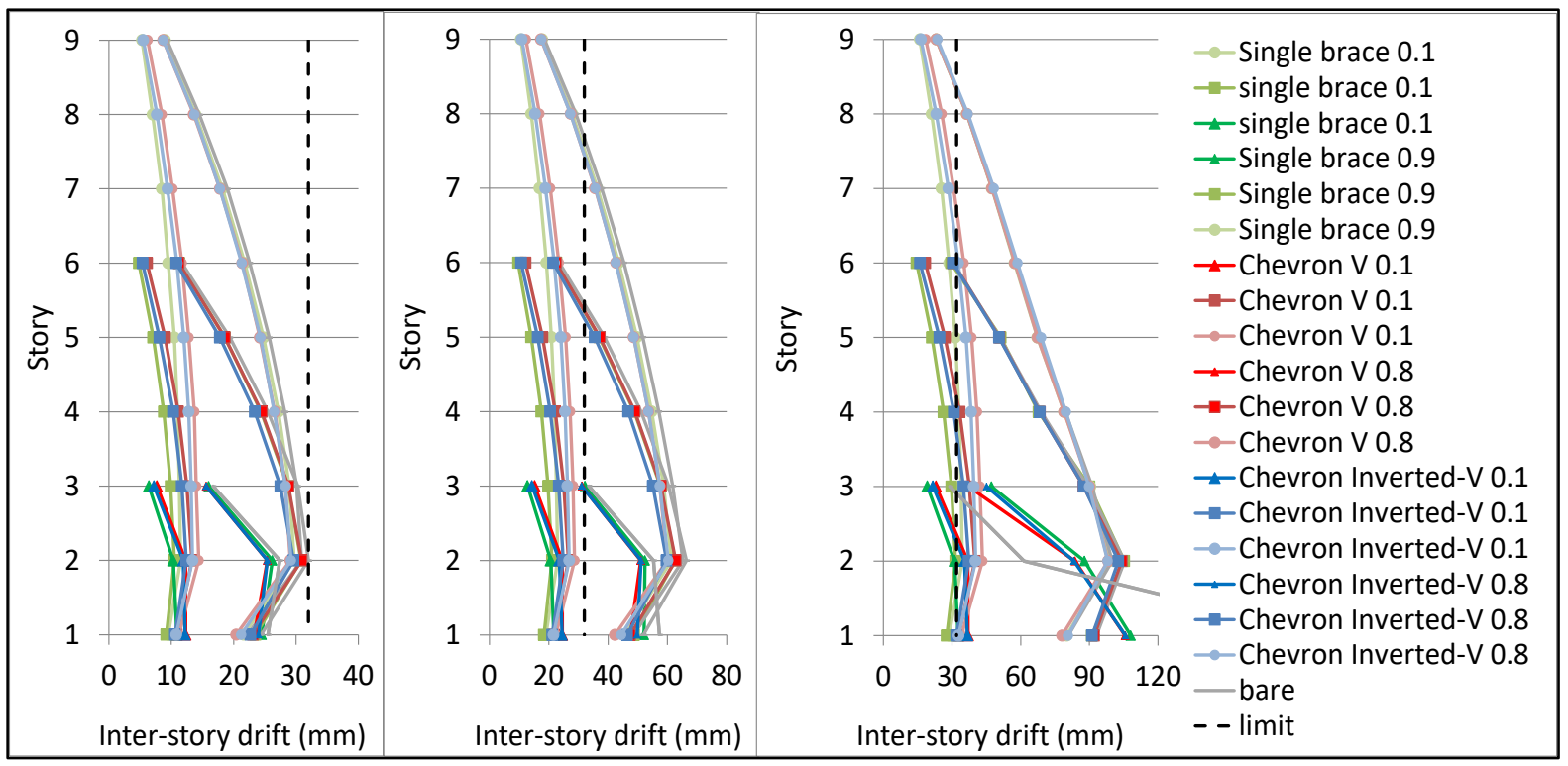
(a) $\mathrm{x} 1$
(b) $\mathrm{x} 2$
(c) $\mathrm{x} 3$

Figure 4. Inter-story drift summary: (a) multiplier of 1, (b) multiplier of 2 and (c) multiplier of 3. 
The Third International Conference on Civil Engineering Research (ICCER) August $1^{\text {st }}-2^{\text {nd }} 2017$, Surabaya - Indonesia

effect of the varying eccentricity. In this case, the eccentricity ratio value ranges from 0.1 to 0.9 for single brace configuration and 0.1 to 0.8 for Chevron $\mathrm{V}$ and Chevron Inverted-V. The maximum eccentricity ratio was computed in such a way the length of the stub was equal for the three configurations. The results of the inter-story drift of the bare frame and drift limit were also plotted in the figure for analysis. It observed that the inter-story drift is highest at the $2^{\text {nd }}$ storey, regardless of the multiplier. The inter-story drift decreases from the second story going upward. The inter-story drift became larger as the multiplier is increased, and the drift limit was exceeded when the multiplier used are 2 and 3 (x2 and $\mathrm{x} 3$ ). It is also interesting to note that the drift limit became very large at the $1^{\text {st }}$ storey when the multiplier was 3. This seems to indicate that soft storey may have occurred at this condition.

\section{B. Effect of Cross-sectional area of BRB}

For the analysis of the effect of cross-sectional area of $\mathrm{BRB}$, the optimum cross sectional area of BRB required for a given eccentricity. The analysis was done for the different BRBF-E configuration and different multiplier. Evidently, the inter-story drift of bare frame will be reduced when the cross sectional area of BRB is increased. Increasing the cross sectional area of the brace
The sizes of buckling-restrained braces available in ETABS were the only one used in the study. With this, the optimum cross sectional area of BRB that satisfied the drift limit per eccentricity ratio from 0.1 to 0.5 for all different seismic load multiplier was determined. The results are shown in Figure 5. It is observed that for multiplier 1, smaller cross sectional areas are adequate to satisfy the drift for all the eccentricity ratios analyzed. However for multiplier 2 and 3, there are cases where there will be no cross sectional area of BRB that would be suitable for satisfying the drift-limit. For the multiplier 2, there is a sudden large increase in the required cross-sectional area when the eccentricity ratio was 0.4 and above. Therefore, it is not suggested to have an eccentricity greater than 0.4 otherwise the size of the BRB would be prohibitively large. For multiplier 3, the required size of BRB that will satisfy the drift limit greatly increased. It is only for the single diagonal braced configuration that that it may be possible to control the drift for reasonable size of the BRB. Notice also that required size of $\mathrm{BRB}$ increases with the increase in the number of storey of the building. With the foregoing observation, it would be helpful to establish a design guide so that for a given building and eccentricity ratio, the size of the BRB can be estimated for a desired performance of the structure.

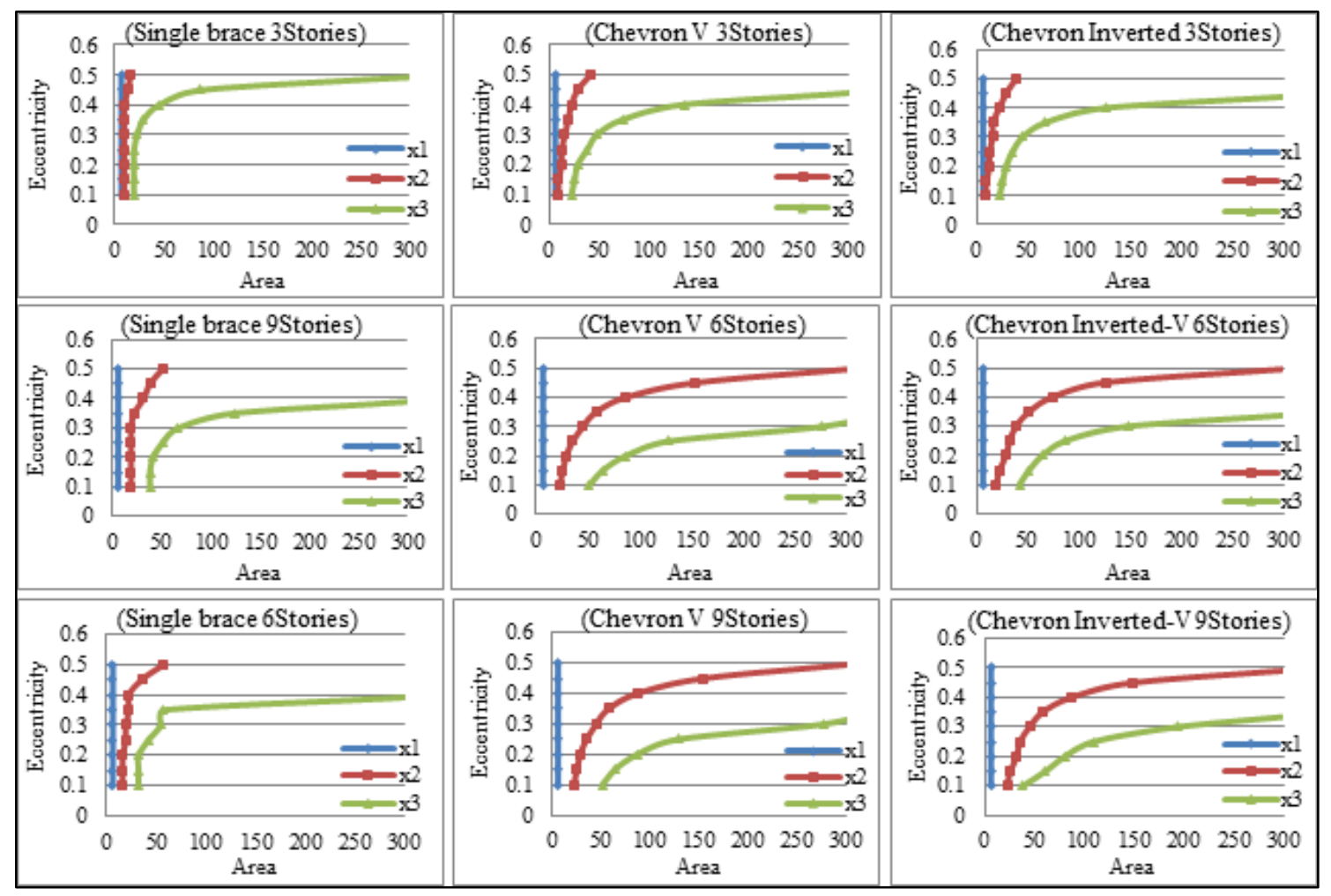

(a) Single brace configuration

(b) Chevron V configuration

(c) Chevron Inverted-V configuration

Figure 5. Plot of eccentricity against designed cross-sectional area of BRB for the following: (a) Single brace configuration,

(b) Chevron V configuration and (c) Chevron Inverted-V configuration.

increases the stiffness of the structure leading to reduced inter-story drift. The smallest possible BRB that will not exceed the drift limit is considered the optimal. 


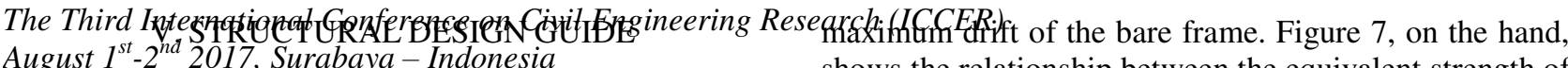

The design guide was made to determine the required cross sectional area of the BRB and its equivalent increase in strength. The bare frame is retrofitted into BRBF-E to satisfy the drift limit. The performance of the BRBF-E under various conditions was analysed to derive for the design guide. The summary of the analysis of various parameters is discussed below.

For the eccentricity ratio, it was observed that small value of eccentricity ratio reduces more both of the interstory drift as compared to large values of eccentricity ratio. For the cross-sectional area of BRB parameter, the optimum cross sectional area of BRB to satisfy the drift limit was determined. Larger inter-story drift is obtained when larger BRB is used. Since larger eccentricity ratios may tend to require very large BRB (especially under higher load multiplier), the eccentricity ratios considered were limited only from 0.1 to 0.5 .

The results on various parameters were studied but it was decided to incorporate only two parameters in the design guide, namely, eccentricity ratio and crosssectional area of BRB. It was found out that these two parameters have more influence on the performance of the BRBF-E. The design guide contains the relationship between the cross sectional area of $B R B\left(A_{B R B}\right)$ and the equivalent strength increase against the maximum drift of the bare frame. Example of these design charts are shown in Figure 6 and Figure 7. Shown in Figure 6 is the relationship between the required $\mathrm{A}_{\mathrm{BRB}}$ and the shows the relationship between the equivalent strength of the BRBF-E and maximum drift of the bare frame.

The process of using the design guide is as follows: First, the existing steel building is analysed and the maximum inter-story drift is determined. If the strength of the building is insufficient (the building exceeds the drift limit), the maximum inter-story drift, eccentricity ratio and BRBF-E configuration will be used to determine the cross sectional area of BRB and its equivalent strength increase to satisfy the drift limit by referring to graphs similar to those shown in Figure 6 to Figure 7. Otherwise, if the existing structure has a sufficient strength and it is desired to increase its strength; the desired increase in strength or equivalent strength increase, eccentricity ratio and BRBF-E configuration were used to determine the maximum drift by referring to a graph similar to Figure 7 . Once the maximum drift is known, refer to a graph similar to Figure 6 to determine the required cross sectional area of BRB. The eccentricity ratio and configuration of BRBF$\mathrm{E}$ depends on the architectural consideration on the structure.

\section{CONCLUSION}

The structural parameters, namely, eccentricity ratio and cross sectional area of BRB have different effects in terms of inter-story drift for every number of stories of the structure.

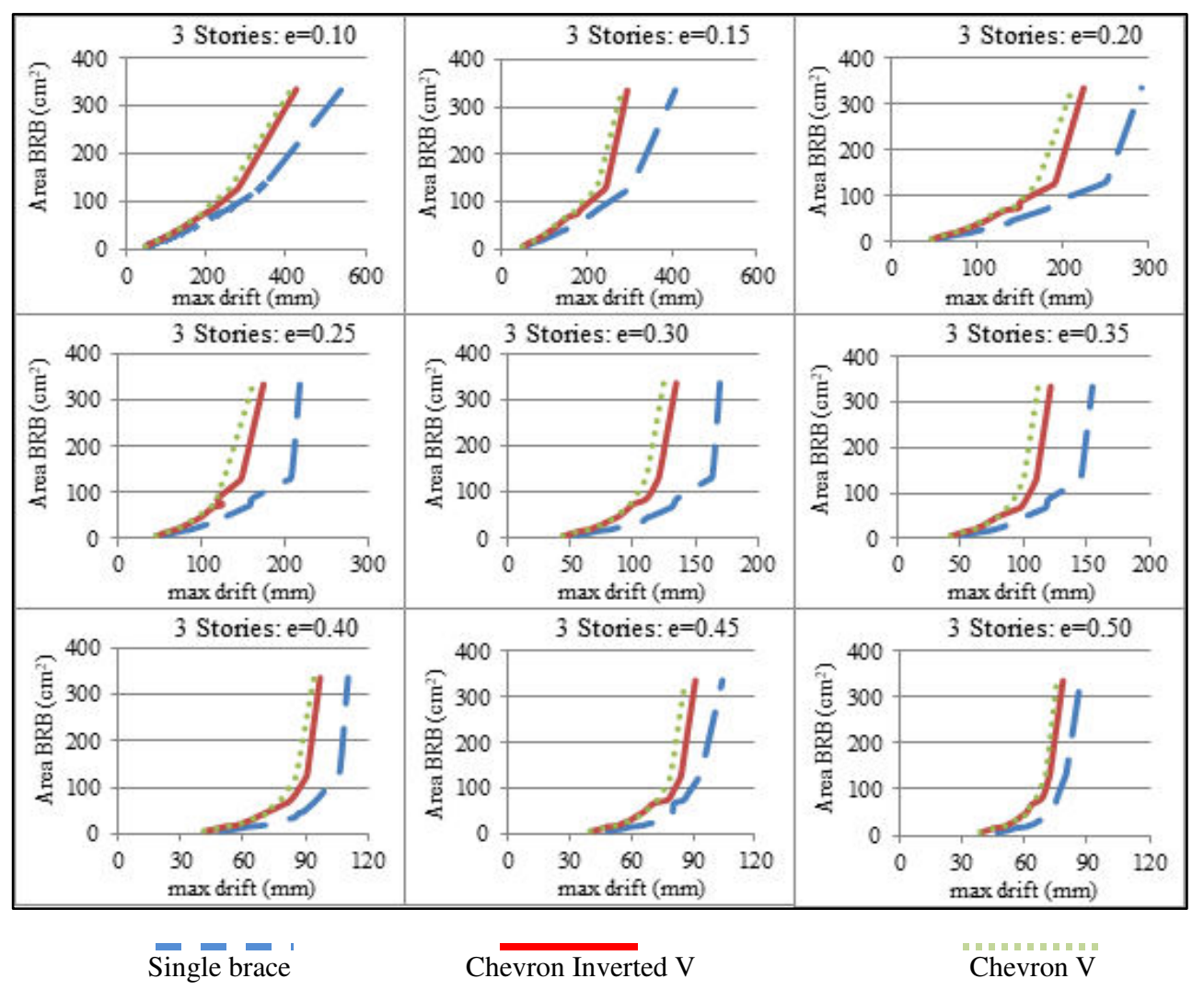

Figure 6. Design Guide Example: $A_{\text {BRB }}$ vs maximum drift for 3 story building 
The Third International Conference on Civil Engineering Research (ICCER) August $1^{\text {st }}-2^{\text {nd }} 2017$, Surabaya - Indonesia

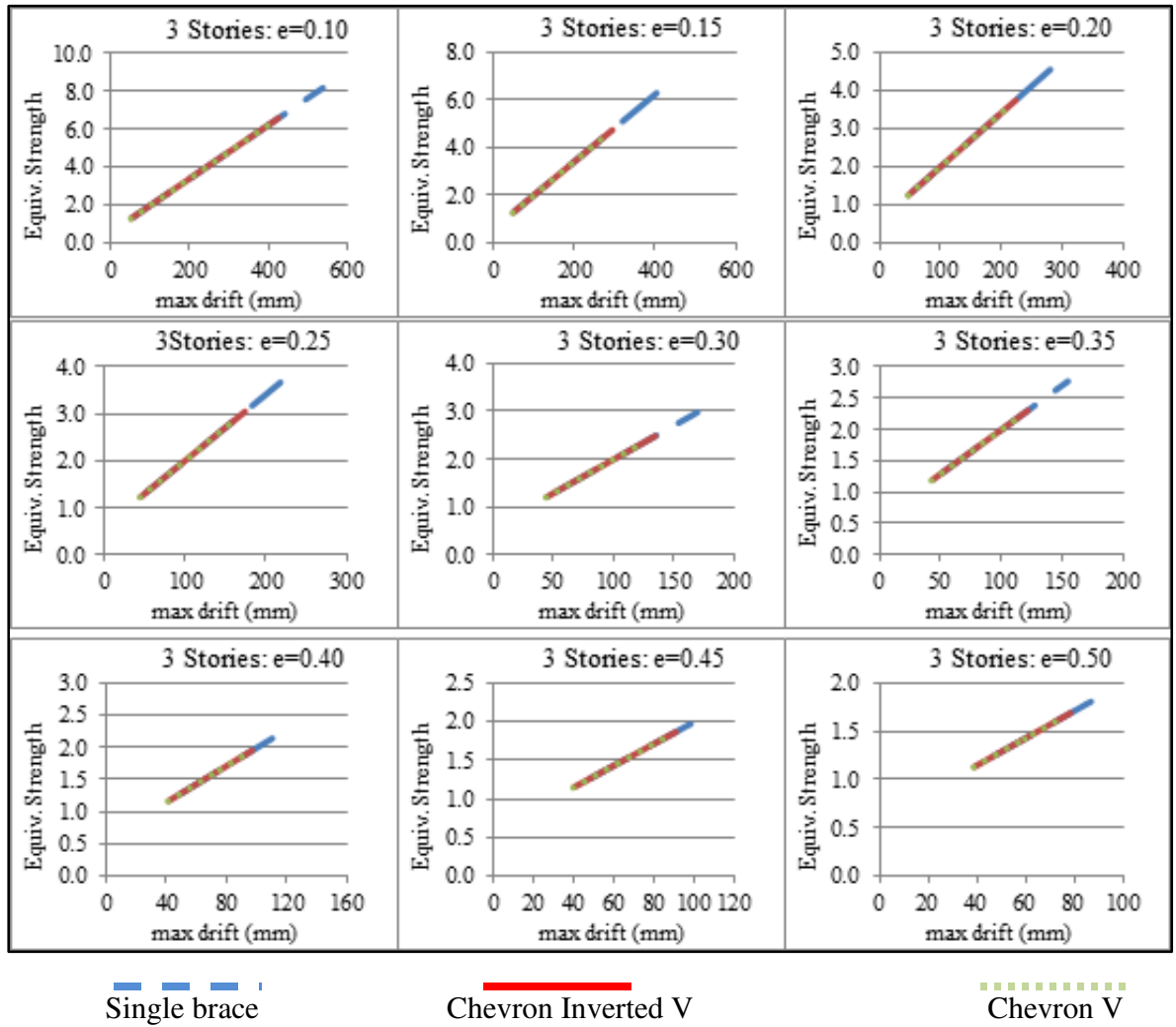

Figure 7. Example of Design Guide: Equivalent strength vs maximum drift for 3 story building

For eccentricity ratio, small eccentricity ratio offers better stability than a large eccentricity ratio, resulting in a remarkable reduction of inter-story drift. Also, the percentage of failure of members increases as the eccentricity ratio increases. This means that bucklingrestrained braces provide more stiffness if the eccentricity ratio is kept minimum.

For the cross sectional area of BRB, increasing the cross sectional area of the BRB leads to the reduction of inter-story drift and percentage failure of members. In addition, the optimized value of cross sectional area of BRB was determined for every configuration and number of stories under different seismic load multiplier for the design guide.

The established design guide provides the required cross sectional area of BRB to satisfy the drift limit and its equivalent strength increase for every BRBF-E configuration. Consequently, the design guide can be used to reduce the inter-story of the bare frame to satisfy the drift limit under three cases such as different beam and column dimensions, different story height and bay length, and different number of stories

\section{ACKNOWLEDGMENT}

The authors would like to express their utmost gratitude to the faculty members and staff of the Civil Engineering
Department of DLSU. Appreciation is also due to all other people - friends, families, relatives, and other DLSU personnel who helped during the experimental tests.

\section{REFERENCES}

[1] A. Dutta and R. O. Hamburger, "Case Study of a 40 Story BRBF Building Located in Los Angeles, Simson Gumpertz and Herger," 2010.

[2] W. N. Deulkar, C. D. Modhera, and H. S. Patil, "Buckling restrained braces for vibration control of building structure," Int. J. Res. Rev. Appl. Sci., vol. 4, no. 4, pp. 363-372, 2010.

[3] R. Sabelli, C. W. Roeder, and J. F. Hajjar, "Seismic Design of Steel Special Concentrically Braced Frame Systems: A Guide for Practicing Engineers," 2013.

[4] G. Prinz and P.Richards, "Seismic performance of buckling restrained braced frames with eccentric configurations," $J$. Struct. Eng., vol. 138, no. 2, pp. 345 - 353, 2012.

[5] Z. Tafheem. and S. Khusru, "Structural behavior of steel building with concentric and eccentric bracing: A comparative study," Int. J. Civ. Struct. Eng., vol. 4, no. 1, pp. 16-19, 2013.

[6] G. Prinz, "Using Buckling-Restrained Braces in Eccentric Configurations," Brigham Young University, 2010.

[7] R. Sabelli, C.W. Roeder, and J.F. Hajjar, "Seismic Design of Steel Special Concentrically Braced Frame Systems: A Guide for Practicing Engineers", National Institute of Standards and Technology. NIST GCR 13-917-24, 2013. 